Elsevier required licence: (c) $<2014>$. This manuscript version is made available under the CC-BY-NC-ND 4.0 license http://creativecommons.org/licenses/bync-nd/4.0/ 


\title{
Professional Interactions with Professor Erskine Crossley
}

\author{
Kenneth J. Waldron \\ Professor, School of Electrical, Mechanical and Mechatronic Engineering \\ University of Technology, Sydney, Ultimo, New South Wales 2007, Australia \\ Professor (Research) Emeritus, Department of Mechanical Engineering \\ Stanford University, Stanford California 94305, U.S.A. \\ And \\ Daniel A. Jacobs \\ Research Fellow, School of Kinesiology \\ University of Michigan, Ann Arbor Michigan, 48109 U.S.A
}

\section{Introduction}

It is a truly amazing privilege to be able to join the celebration of the hundredth birthday of Professor Erskine Crossley. This presentation is restricted to those areas in which our own professional activities have intersected with those of Professor Crossley.

\section{Constraint Analysis}

Professor Waldron's first technical contact with Professor Erskine Crossley happened while he was a master's student at the University of Sydney. He had taken a course in mechanism kinematics from Professor Jack Phillips and had become interested in the problem of constraint analysis: at least that is the name that was later used for it. Crossley had recently published Reference [1], so Waldron's mentors: Jack Phillips and Ken Hunt made sure he knew about it. It was actually the first of a series of papers on related subjects $[2,3]$. Even at that time Crossley had formed a collaboration with Professor Ken Hunt. That collaboration continued for many years and would produce very significant results. Waldron subsequently took the constraint analysis problem with him to Stanford where it formed the starting point of his doctoral research.

In 1964 the Journal of Mechanisms was first published by Pergamon Press with Professor Crossley as Editor-in-Chief. As a private journal published in Europe it provided a first class archive that was an alternative to the ASME Transactions Journal of Engineering for Industry, which was the principal archive for papers in mechanism kinematics at the time. A number of Waldron's early papers were published in the Journal of Mechanisms.

Of course it was several years later before Waldron actually met Professor Crossley. It was at the ASME Mechanisms Conference in 1968 that Crossley hosted at Georgia Institute of Technology. Waldron had attended the last of the Purdue Mechanisms Conferences in 1966. The Georgia Tech Conference was the first one held away from Purdue. Waldron does remember that Professor Crossley invited the international 
participants to a dinner at his house. Since Waldron was still a graduate student at Stanford, he didn't feel he was an adequate representative of Australia, but was invited anyway, and very much enjoyed the event.

\section{IFToMM}

IFToMM stands for the International Federation for Theory of Mechanisms and Machines. It was founded at a meeting in Zakopane, Poland in 1969. The modern version of the name: IFToMM, the International Federation for Promotion of Mechanism and Machine Science came much later, around 1997. Professor Crossley represented the U.S.A. at the 1969 meeting. Professor I.I. Artobolevsky of the U.S.S.R. was the founding President. Crossley was the founding Vice President, and later served a term as Secretary General. We believe he was a principal author of the IFToMM Constitution, for which Waldron is now responsible as chair of the Constitution Committee.

The Secretary General of IFToMM is the officer responsible for all official communications. In many ways this is the most visible member of the Executive Council.

IFToMM holds a World Congress every four years: the next one will be in Taipei in 2015. It also sponsors many Technical Committees and Permanent Commissions that oversee activities in technical fields of mechanism and machine science. Professor Crossley proposed that the Journal of Mechanisms, of which he was still Editor-in-Chief, become the official journal of IFToMM. This proposal was welcomed by the IFToMM Executive Council who voted, however, to rename the journal Mechanism and Machine Theory to correspond with the name of IFToMM itself. The journal continues to this day to function as the official journal of IFToMM. Pergamon Press was acquired by Elsevier in 1992 and the journal is now published under the Elsevier imprint. Shortly after its adoption as the official journal, Professor Crossley passed the editorship of Mechanism and Machine Theory to Professor John Uicker.

Of course, Waldron did not know much of this until much later, when he became active in IFToMM himself, ultimately serving as President from 2000 through 2007.

\section{Modeling Impacts}

Waldron visited Professor Crossley at the University of Massachusetts in 1973. Professor Kenneth Hunt was visiting there at the time on sabbatical leave from Monash University. Waldron remembers Professor Crossley showing him an experimental rig that they were using to characterize impacts. The configuration was a steel ball striking a steel plate. Waldron was not familiar with the mechanics involved at the time, so although they were clearly doing careful experiments, it did not mean much to him.

Much, much later in 2008 Waldron's student, now Dr. Daniel Jacobs, became interested in modeling the impact between a foot of a dynamically running robot and the ground. The most useful paper in the literature turned out to be one published in 1975 by Hunt and Crossley.

The Hertz model is a local deformation model for linearly elastic solids. Hertz solved the static equilibrium equations for the pressure distribution of several different impactor shapes. The most commonly referenced solutions are a sphere on a rigid flat, a sphere on 
another sphere, and a sphere on a spherical seat. The contact force from the Hertz model is a power law function of the interference, the material properties, and the radius of the impacting elements. However, many systems are not linearly elastic and one of the grand challenges of the field has been to find suitable methods for modeling systems that exhibit nonlinear viscoelastic and plastic behaviors.

One of the first and most popular viscoelastic models based on Hertz's elastic theory was a dynamic model presented by Hunt and Crossley [4]. The realistic force displacement profiles and the computational ease of application of the Hunt-Crossley model have driven adoption for almost forty years. In the Hunt and Crossley model, the viscoelastic effects that had been previously empirically measured were modeled with a nonlinear damper acting in parallel to the Hertz spring. For compact solid bodies impacting at low velocities in nearly elastic collisions, Hunt and Crossley found an empirical value for the damping constant by relating the total energy loss using Newton's coefficient of restitution to the maximum strain energy stored.

The equations describing the Hunt-Crossley model [4] are shown below:

$$
\begin{aligned}
& F=\lambda x^{n} \dot{x}+k x^{n} \\
& e=1-\alpha v_{i} \\
& \lambda=\frac{3}{2} \alpha k
\end{aligned}
$$

Here $x$ is the depth of penetration, $k$ and $n$ are constants from the Hertz theory describing the static behavior of the material, $F$ is the contact force, $e$ is the effective coefficient of restitution, and $\alpha$ is another constant that describes dynamic behavior.

Over the past several decades, the Hunt-Crossley model has been used to describe contact interactions in many different areas. In Biomechanics, Sherman et al. used the Hunt Crossley model for muscle-driven simulations of human locomotion [5]. Muthukumar et al. [6] used the Hunt-Crossley model to improve simulations of pounding between buildings during earthquakes. Shkolnik et al. [7] used a Hunt-Crossley model to represent ground contact in bounding experiments using the little dog robotic platform.

One of the main advantages of the Hunt-Crossley model is that the nonlinear damping element is a function of displacement and velocity, which does not generate discontinuous contact forces instantaneously at contact like the linear dampers in models such as Kelvin-Voigt. The stiffness parameter, $k$, and the power parameter, $n$, can be found easily through Hertz's elastic theory. In order to calculate the parameter, $\alpha$, a set of experimental impact data (which is not trivial to measure) is needed. The damping parameter, $\lambda$, is significantly more challenging to evaluate because there is no clear relationship between the material properties of the impactors and the damping.

In the closing, remarks of the original paper, Hunt and Crossley suggested that the method described in the paper might be useful for studying other systems, potentially those far removed from the original elastic application. Many authors $[12,13,14,15,16$, $17,18]$ have taken up the challenge of refining the method of the original Hunt-Crossley paper, developing improved methods for relating the damping parameter to the coefficient of restitution analytically for impacts away from the nearly elastic region. 
The applicability of the Hunt-Crossley model is limited to the range where the coefficient of restitution can be reasonably approximated with the above simple linear function of incident velocity. Empirical measurements of spheres of various materials in collisions have confirmed that the linear approximation for the coefficient of restitution only works in a very small region $[8,9,10,11]$.

Zhang and Sharf [18] and Jacobs and Waldron [17] showed that a nonlinear model between the coefficient of restitution and the incident displacement rate improves the approximation of the coefficient of restitution especially when the data being modeled includes elastic and plastic collisions. Recently, Gonthier et al. [15] and Zhang and Sharf [16] derived exact implicit relationships for the damping parameter but they are limited by the use of Newton's (kinematic form) of the coefficient of restitution.

Jacobs [19] presents a nonlinear implicit representation of Stronge's (energetic form) of the coefficient of restitution as a function of the model parameters together with experimental validation and implementation in numerical simulations.
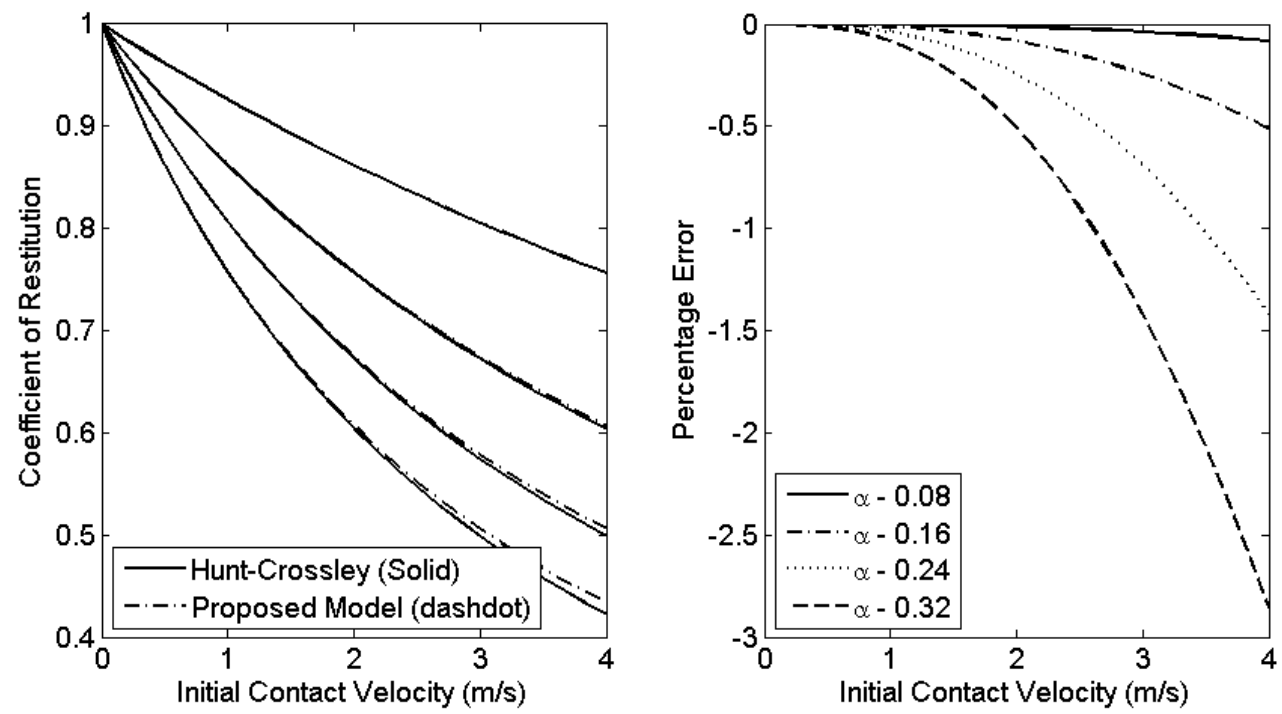

Figure 1: (left) Coefficient of Restitution Comparison for Hunt-Crossley and Proposed Model for $\alpha$ values of $0.08,0.16,0.24,0.30$. (right) Percentage error of the Proposed Model

For a preliminary validation of the proposed calculations for the damping parameter, we compared the coefficient of restitution predicted by the Jacobs model to the HuntCrossley model in simulation. The geometry of the impact is assumed to be a sphere on a rigid flat. The sphere is aluminum with an Elastic Modulus of $68.9 \mathrm{GPa}$, Poisson's Ratio of 0.33 and a radius of $0.02 \mathrm{~m}$. Hunt and Crossley reported that for steel, bronze, and ivory, the values of $\alpha$ range from $0.08-0.32 \mathrm{sec} / \mathrm{m}$. The four materials studied were uniformly chosen in the same range. Following Hertz's calculations, the calculated stiffness $\mathrm{k}$ is $1.4580 \mathrm{e}+10 \mathrm{~N} / \mathrm{m}^{\wedge}(3 / 2)$. In the first part of the simulation experiment, the values of the coefficient of restitution for the Hunt-Crossley model were calculated with a custom Matlab script created by the MotionGenesis software. Secondly, the parameters 
$k, n, v_{i}$ and $e_{\text {hunt-crossley }}$ were input into a zero crossing algorithm to find the damping parameter, $\lambda$ and the new parameters were integrated as before for the proposed model. The results of those trials and the percentage approximation error are plotted in Figure 1.

\section{Summary}

We have reviewed several areas in which Professor Crossley's long professional career has influenced those of the authors. The work on modeling impact has turned out to be particularly influential.

\section{References}

[1] Crossley, F. R. E., "A Contribution to Gruebler's Theory in the Number Synthesis of Plane Mechanisms", 1964, J. Eng. Ind., 86, pp. 1-5.

[2] Crossley, F.R.E., "The Permutation of Kinematic Chains of Eight Members or Less from a Graph Theoretic Viewpoint," Developments in Theoretical and Applied Mechanics, Vol.2, 1965, pp. 467-486.

[3] Trevor H. Davies and F. Erskine Crossley, "Structural analysis of plane linkages by Franke's condensed notation." J. Mechanisms, Vol. 1, p. 171- 83. 1966.

[4] Hunt, K. H., and Crossley, F. R. E., 1975. "Coefficient of restitution interpreted as damping in vibroimpact". J. Applied Mechanics, 42(2), pp. 440-445.

[5] Sherman, M. A., Seth, A., and Delp, S. L., 2011. "Simbody: multibody dynamics for biomedical research". Procedia IUTAM, 2(0), pp. 241-261.

[6] Muthukumar, S., and DesRoches, R., 2006. "A hertz contact model with nonlinear damping for pounding simulation". Earthquake Engineering \& Structural Dynamics, 35(7), pp. 811-828.

[7] Shkolnik, A., Levashov, M., Manchester, I. R., and Tedrake, R., 2011. "Bounding on rough terrain with the LittleDog robot". IJRR, 30(2), pp. $192-215$.

[8] Tabor, D., 1948. "A simple theory of static and dynamic hardness". Proc. Royal Society. Series A, 192(1029), pp. 247-274.

[9] Kuwabara, G., and Kono, K., 1987. "Restitution coefficient in a collision between two spheres". Japanese J. Applied Physics, 26(Part 1, No. 8), pp. 1230-1233.

[10] Gugan, D., 2000. "Inelastic collision and the hertz theory of impact". American J. Physics, 68(10), p. 920.

[11] Zhang, Y., and Sharf, I., 2011. "Force reconstruction for low velocity impacts using force and acceleration measurements". J. Vibration and Control, 17(3), pp. 407-420.

[12] Herbert, R. G., and McWhannell, D. C., 1977. "Shape and frequency composition of pulses from an impact pair". J. Engineering for Industry, 99(8), p. 513518. 
[13] Lankarani, H. M., and Nikravesh, P. E., 1990. "A contact force model with hysteresis damping for impact analysis of multibody systems". J. Mechanical Design, 112(3), pp. 369-376.

[14] Marhefka, D. W., and Orin, D. E., 1999. "A compliant contact model with nonlinear damping for simulation of robotic systems". IEEE Trans. Systems, Man and Cybernetics, A: 29(6), pp. 566-572.

[15] Gonthier, Y., McPhee, J., Lange, C., and Piedbuf, J.-C., 2004. "A regularized contact model with asymmetric damping and dwell-time dependent friction". Multibody System Dynamics, 11(3), pp. 209-233.

[16] Zhang, Y., and Sharf, I., 2004. "Compliant force modelling for impact analysis". Proc. ASME IDETC, 2004(46954), pp. 595-601.

[17] Jacobs, D. A., Waldron, K. J., 2008. "A nonlinear model for simulating contact and collision". Proc. 11th CLAWAR, pp. 930-936.

[18] Zhang, Y., and Sharf, I., 2009. "Validation of nonlinear viscoelastic contact force models for low speed impact". J. Applied Mechanics, 76(5), pp. 051002-12.

[19] Jacobs, D.A., "Dynamic Simulation of Legged Robot," Doctoral Dissertation, Stanford University, October 2012. 